\title{
Systems biology analysis of the lung cancer-related secretome
}

\author{
LIN FENG $^{1 *}$, YIKUN YANG $^{2 *}$, MIN LI $^{1}$, JIE SONG $^{1}$, YANNING GAO $^{1}$, SHUJUN CHENG $^{1}$ and TING XIAO \\ ${ }^{1}$ State Key Laboratory of Molecular Oncology, Beijing Key Laboratory for Carcinogenesis and Cancer Prevention, \\ National Cancer Center/National Clinical Research Center for Cancer/Cancer Hospital, Chinese Academy \\ of Medical Sciences and Peking Union Medical College; ${ }^{2}$ Department of Thoracic Surgery, \\ National Cancer Center/National Clinical Research Center for Cancer/Cancer Hospital, Chinese Academy \\ of Medical Sciences and Peking Union Medical College, Beijing 100021, P.R. China
}

Received September 14, 2017; Accepted May 18, 2018

DOI: $10.3892 /$ or.2018.6509

\begin{abstract}
Tumorigenesis is closely and highly associated with developmental biology. The present study aimed to discover and identify marker proteins strongly associated with the occurrence and development of non-small cell lung cancer (NSCLC) in humans and to provide new ideas for investigating lung cancer markers by combining biological analyses of embryonic development. We established primary cultures for samples of tumor and control tissues from 9 patients with NSCLC and collected conditioned medium (CM). Subsequently, we used liquid chromatography and linear ion trap (LTQ) mass spectrometry to isolate and identify proteins in CM samples. Data mining of free proteins was conducted using the analogous analysis strategy in systems biology to obtain important lung cancer-associated proteins (plasma markers). Proteins with significant plasma enrichment in lung cancer patients were detected via enzyme-linked immunosorbent assay (ELISA). We identified 987 high-confidence proteins and established a primary database of free proteins associated with lung cancer. Furthermore, 511 high-confidence proteins were present in CM from primary tissue cultures from at least 2 of the 9 examined cases of lung cancer. Analysis using Gene Set Enrichment Analysis (GSEA) software revealed significant enrichment for 197 proteins from the CM of lung cancer samples in maternal-placental interface expression profiles for a mid-term placenta with strong invasiveness relative to RNA expression profiles for a human
\end{abstract}

Correspondence to: Professor Ting Xiao, State Key Laboratory of Molecular Oncology, Beijing Key Laboratory for Carcinogenesis and Cancer Prevention, National Cancer Center/National Clinical Research Center for Cancer/Cancer Hospital, Chinese Academy of Medical Sciences and Peking Union Medical College, 17 Panjiayuannanli, Chaoyang, Beijing 100021, P.R. China

E-mail: xiaot@cicams.ac.cn

*Contributed equally

Keywords: lung cancer,conditioned medium,embryonic development, systems biology, hypoxanthine phosphoribosyltransferase 1 full-term placenta after delivery. ELISA results demonstrated that hypoxanthine phosphoribosyltransferase 1 (HPRT1) was associated with worse rates of disease-free survival (DFS) and overall survival (OS). The biological behaviors of embryonic implantation are similar to those of tumor invasion and metastasis, and the information obtained regarding developmental biology could facilitate the interpretation of tumor invasion and metastasis. Therefore, similar biological behaviors combined with analyses at different molecular levels from the perspective of systems biology will provide new ideas for tumor research.

\section{Introduction}

Lung cancer is also known as primary bronchogenic carcinoma and is a type of malignancy that originates in the bronchial epithelium. Lung cancer is one of the most common malignant tumors and the most deadly cancer worldwide (1). In recent years, due to population aging, smoking, environmental pollution and other factors, the incidence and mortality rates of lung cancer have tended to increase across the globe, especially in China and other developing countries (2). Biomarkers are of great significance for the diagnosis and treatment of diseases, particularly cancers. With the development of large-scale proteomic technology, especially biological mass spectrometry (MS), proteomic technology has become a mainstream technological approach in cancer biomarker discovery.

Embryos and tumors share great similarities in many respects. In 1829, French scientists, Lobstein and Recamier, first proposed the concept of an embryonic origin of tumors, that is, cancer occurs due to the continued proliferation of embryonic cells present in the body (3). In the 1970s, Pierce developed the theory of 'cancer, a problem of developmental biology' and noted that tumorigenesis is closely and strongly related to developmental biology (4). Due to the similarity between tumors and embryonic cells during gestation in terms of growth, invasion and immune system suppression, it has been proposed in recent years that we should think of and study tumors from an evolutionary perspective (5-7). With the development of experimental techniques and the increase in research investigations, the early hypothesis that embryonic development and tumorigenesis are closely related has increasingly been confirmed. 
In our preliminary study, to eliminate the interference of high-abundance proteins in the blood and enrich lung cancer-specific markers in body fluid, we established a new primary organ culture model to detect the free proteins released by tumor cells into the bloodstream (8). In the present study, we used the research system for tumor-associated proteins in body fluid that was established in our preliminary study. We also established primary cultures of tumor and control tissue samples from non-small cell lung cancer (NSCLC) patients and collected conditioned medium (CM). We then used liquid chromatography (LC) and linear ion trap (LTQ) MS to isolate and identify the full spectrum of the total proteins in CM samples. Subsequently, we used BRB-ArrayTools (http://linus.nci.nih.gov/BRB-ArrayTools.html), ArraySVG and other programs and analyzed MS data using the spectral counts produced by label-free quantitative proteomics as the quantitative parameter. We used the Gene Set Enrichment Analysis P (GSEA-P) program to conduct enrichment analysis of the free proteins identified in tumor tissue $\mathrm{CM}$ based on the maternal-placental interface expression profile data at different stages. Data mining of free proteins was conducted to identify important lung cancer-associated plasma proteins.

\section{Materials and methods}

Sample collection. Tissue samples of lung cancer patients for the present study were all taken from hospitalized patients in the Department of Thoracic Surgery at the Cancer Hospital of the Chinese Academy of Medical Sciences and Peking Union Medical College. When the specimens were obtained, none of the patients had received physical or chemical treatments. We conducted a comprehensive collection of patient clinical data. The histopathological types of surgically resected tumor tissues were determined by senior pathologists based on the World Health Organization (WHO) classification of lung cancer tissue. Tumor staging was determined based on the 7th edition of the Union for International Cancer Control (UICC) tumor-node-metastasis (TNM) staging system. During the period from September 2005 to October 2006, we collected fresh tumor and control tissue samples for primary culture from 9 patients, including 5 patients with squamous cell carcinoma (SCC), 3 patients with adenocarcinoma (ADC) and 1 patient with large cell carcinoma (LCLC). The clinical data of the patients are listed in Table I.

Peripheral blood samples were collected from July 2007 to November 2007 from 59 NSCLC patients (38 males and 21 females; mean age, 61.8 years) who underwent surgery at the National Cancer Center/National Clinical Research Center for Cancer/Cancer Hospital of Chinese Academy of Medical Sciences and Peking Union Medical College. The cohort of the NSCLC patients included 26 patients with lung SCC and 33 patients with lung ADC. There were 40 stage I-II cases and 19 stage III cases. All patients provided written informed consent before surgery, and treatments were performed in accordance with the current ethical principles of the Independent Ethics Committee, Cancer Hospital, Chinese Academy of Medical Sciences. Peripheral blood samples were collected via venipuncture prior to surgery and preserved in EDTA-coated tubes. Samples were centrifuged at $4^{\circ} \mathrm{C}$ for $10 \mathrm{~min}$ at $1,000 \mathrm{x}$ g to separate plasma from blood cells.
Supernatants were collected, divided into aliquots and stored at $-80^{\circ} \mathrm{C}$ until use. Disease-free survival (DFS) was defined as the interval between surgery and recurrence; if recurrence was not diagnosed, the date of death or last follow-up was recorded. Overall survival (OS) was defined as the interval between surgery and death. After surgery, patients were followed up for over eight years or until death. At the end of the follow-up period (11-99 months, with a mean of 74 months), tumor recurrence had been identified in 33 (55.0\%) patients; 27 (45.0\%) patients had died at the time of data censorship.

Primary tissue culture and CM collection. We chose different control tissues depending on pathological characteristics. For SCC, the control tissue was normal bronchial tissue from the same patient. For ADC and large cell lung cancer (LCLC), the control tissue was normal lung tissue from the same patient. In all cases, the distance between the control and tumor tissues was $>3 \mathrm{~cm}$. Samples of paracancerous bronchial/lung tissues and lung cancer tissues that were dissected from the body within 30 min were cut into small pieces with volumes of approximately $5 \mathrm{~mm}^{3}$ using a scalpel. Tissue pieces were placed into collagen-coated gridded dishes, and LHC-9 medium (Invitrogen; Thermo Fisher Scientific, Inc., Waltham, MA, USA) was added carefully and slowly in a dropwise manner to prevent disruption of these pieces. The dishes were placed in a culture box, which was then filled with a gas mixture of $50 \% \mathrm{~N}_{2}, 45 \% \mathrm{O}_{2}$ and $5 \% \mathrm{CO}_{2}$. The culture box was placed on a shaker, with a shaking frequency of 8-10 times $/ \mathrm{min}$. $\mathrm{CM}$ was collected after $24 \mathrm{~h}$ of incubation in a $36.5^{\circ} \mathrm{C}$ incubator. The collected CM was added to an Amicon Ultra tube (cat no. UFC900596; Millipore; Merck KGaA, Darmstadt, Germany) and then centrifuged for $45 \mathrm{~min}$ at $4,000 \mathrm{x}$ g and $4^{\circ} \mathrm{C}$. This process was performed to desalinate and concentrate the sample.

\section{LC-MS analysis and identification of proteins released into CM by cells}

Enzyme digestion of proteins in CM. A total of $30 \mu \mathrm{g}$ of CM proteins was dissolved in $50 \mu \mathrm{l}$ of solution containing $8 \mathrm{M}$ urea and $10 \mathrm{mM}$ dithiothreitol (DTT); $100 \mu \mathrm{l}$ of $50 \mathrm{mM} \mathrm{NH}_{4} \mathrm{HCO}_{3}$ solution was then added, and the sample was incubated in a $37^{\circ} \mathrm{C}$ water bath for $4 \mathrm{~h}$. Subsequently, $2.5 \mu \mathrm{l}$ of $1 \mathrm{M}$ indoleacetic acid (IAA) solution was added, and protein alkylation was completed during $1 \mathrm{~h}$ of reaction at room temperature in the dark. Next, $40 \mu \mathrm{l}$ of acetonitrile (ACN; a final concentration of 10\%) and $30 \mu \mathrm{l}$ of $50 \mathrm{mM} \mathrm{NH}_{4} \mathrm{HCO}_{3}$ were added to the mixture, followed by sequencing-grade trypsin at a protein-to-enzyme ratio of 100:1 and all components were well mixed. After the entire system was mixed by shaking, the mixture was incubated in a $37^{\circ} \mathrm{C}$ water bath for $2 \mathrm{~h}$. To ensure the enzyme digestion effects, trypsin was added $2 \mathrm{~h}$ later in a ratio of 100:1, and the incubation was continued for a total of $16 \mathrm{~h}$ after mixing. The reaction solution was acidified with 5\% formic acid (FA) to terminate the reaction.

SPE desalination. The desalting column was an LC-18 solid-phase extraction (SPE) column (Supelco Inc., Bellefonte, PA, USA). The desalting steps were as follows: The SPE column was activated with $2 \mathrm{ml}$ of ACN and equilibrated with $2 \mathrm{ml}$ of $0.1 \%$ trifluoroacetic acid (TFA) solution in water; 
Table I. Demographic features of primary culture tissue samples.

\begin{tabular}{lllclll}
\hline No. & Sex & Age & $\begin{array}{c}\text { Histopathological } \\
\text { types }\end{array}$ & TNM staging & $\begin{array}{c}\text { Pathological } \\
\text { staging }\end{array}$ & Differentiation degree \\
\hline 25 & Female & 75 & ADC & T2N0M0 & IB & Moderately \\
26 & Male & 68 & ADC & T2N2M0 & IIIA & Moderately \\
27 & Male & 73 & SCC & T2N0M0 & IB & Moderate-poorly \\
29 & Male & 65 & LCLC & T3N1M0 & IIIA & Poorly \\
30 & Male & 52 & SCC & T2N1M0 & IIB & Moderately \\
31 & Male & 37 & SCC & T4N2M0 & IIIB & Moderately \\
33 & Female & 61 & SCC & T2N1M0 & IIB & Poorly \\
34 & Male & 58 & SCC & T3N2M0 & IIIA & Well \\
38 & Male & 45 & ADC & T3N1M0 & IIIA & Moderate-poorly \\
\hline
\end{tabular}

ADC, lung adenocarcinoma; ASC, adenosquamous carcinoma of the lung; SCC, squamous cell carcinoma; SCLC, small cell lung cancer; LCLC, large cell lung carcinoma.

the peptide mixture was slowly added to the column until all of the samples had entered the column matrix; $2 \mathrm{ml}$ of $0.1 \%$ TFA solution in water was added for desalting; elution was conducted by adding $1.5 \mathrm{ml}$ of eluent (containing $80 \% \mathrm{ACN}$ and $0.1 \%$ TFA) and the eluate was collected, lyophilized and stored at $-20^{\circ} \mathrm{C}$.

LC-ESI-MS/MS separation and identification of peptide mixture. Reversed-phase liquid chromatography-tandem mass spectrometry (RPLC-MS/MS) was used to analyze the peptide mixture using a Thermo Finnigan ${ }^{\mathrm{TM}}$ LTQ system (Thermo Fisher Scientific, Inc.) with an electrospray ionization (ESI) ion source and the high-throughput analysis mode. A nano-LC system (Thermo Fisher Scientific, Inc.) was run with an LC-Packing system, equipped with a Famos autosampler system, Swithos loading pump and Ultimate elution pump; the system was monitored using Dionex chromatography software. Two RP-C18 trap columns (Supelco Inc.) were connected to the ten-port valve. When samples were being loaded to one column, inverted elution was conducted on the other column, and a PicoFrit ${ }^{\mathrm{TM}}$ analytical column (BioBasic ${ }^{\circledR} \mathrm{C} 18$, $5 \mu \mathrm{m}, 75 \mu \mathrm{m}$ i.d. x $10 \mathrm{~cm}, 15 \mu \mathrm{m}$ i.d. spray tip; New Objective, Woburn, MA, USA) was then used. Elution chromatography was conducted on the Ultimate system (Thermo Fisher Scientific, Inc.) and the eluted components directly entered the MS instrument through the ESI ion source. The LC conditions were as follows: Mobile phase A, 5\% ACN-95\% water; and mobile phase $\mathrm{B}, 0.1 \%$ FA- $80 \%$ ACN solution.

Database search. The tandem mass spectral database was queried using the SEQUEST engine of the Bioworks3.1 software (Thermo Fisher Scientific, Inc.). We used the International Protein Index (IPI) human protein database v3.07 in the Fasta database (ftp://ftp.ebi.ac.uk/pub/databases/IPI). The search settings for peptide amino acid sequence variable modifications were $\mathrm{C}(+57.02 \mathrm{Da}), \mathrm{M}(+15.99 \mathrm{Da})$, a false discovery rate (FDR) of $<0.01$ and a peptide mass tolerance of $1.5 \mathrm{Da}$. The reverse database was established by reversing the amino acid sequence of each protein. BuildSummary software was used to integrate and compare the Sequest search results. The data filtering parameters were set as follows: Xcorr $\geq 1.9,1+$; Xcorr $\geq 2.2,2+$; Xcorr $\geq 3.75,3+$; DeltCn $\geq 0.1$; Rsp $\leq 4$.

Bioinformatic analysis of the CM free protein database. This process used the IPI as the index for data processing. We selected all proteins with no less than two matching peptides and eliminated redundant proteins due to homology for all samples.

Gene Ontology (GO) was combined with the SWISS-PROT protein database (http://www.uniprot. org/uniprot/?query=reviewed\%3Ayes) to analyze the biological processes, cellular localization and molecular functions of the proteins in the CM. BRB-ArrayTools software (http://linus.nci. nih.gov/BRB-ArrayTools.html) (9) was used for the identification, cluster analysis and enrichment analysis for differential proteins. Gene Set Enrichment Analysis (GSEA) was first proposed by Mootha et al in 2003 (10). It was later modified by Subramanian et al (11) to introduce weighted scores to replace uniform scores. GSEA-P 2.0 software was used to conduct enrichment analysis of the free proteins identified in tumor tissue CM based on the placental-maternal interface expression profiles at different stages. GSEA analysis first uses the gene expression profile data of two groups that are known to have different phenotypes, and distribution L can be obtained by sorting genes based on the correlation between gene expression profiles and phenotypes. The data to be analyzed were named $\mathrm{S}$, which is a series of data with common characteristics. For example, $\mathrm{S}$ may be gene-coding products in the same metabolic pathway, genes located in the same chromosomal band or genes/proteins with the same functions, as indicated by GO analysis. Via GSEA analysis, we ultimately obtained the enrichment conditions of data $S$ in the existing distribution L. The data could be either randomly distributed or enriched in data closely related to a certain phenotype. The latter may indicate biological significance.

Enzyme-linked immunosorbent assay (ELISA). Hypoxanthine phosphoribosyltransferase 1 (HPRT1) protein concentrations in plasma were assessed using ELISA according to the manufacturer's instructions. ELISA kits for HPRT1 were purchased 


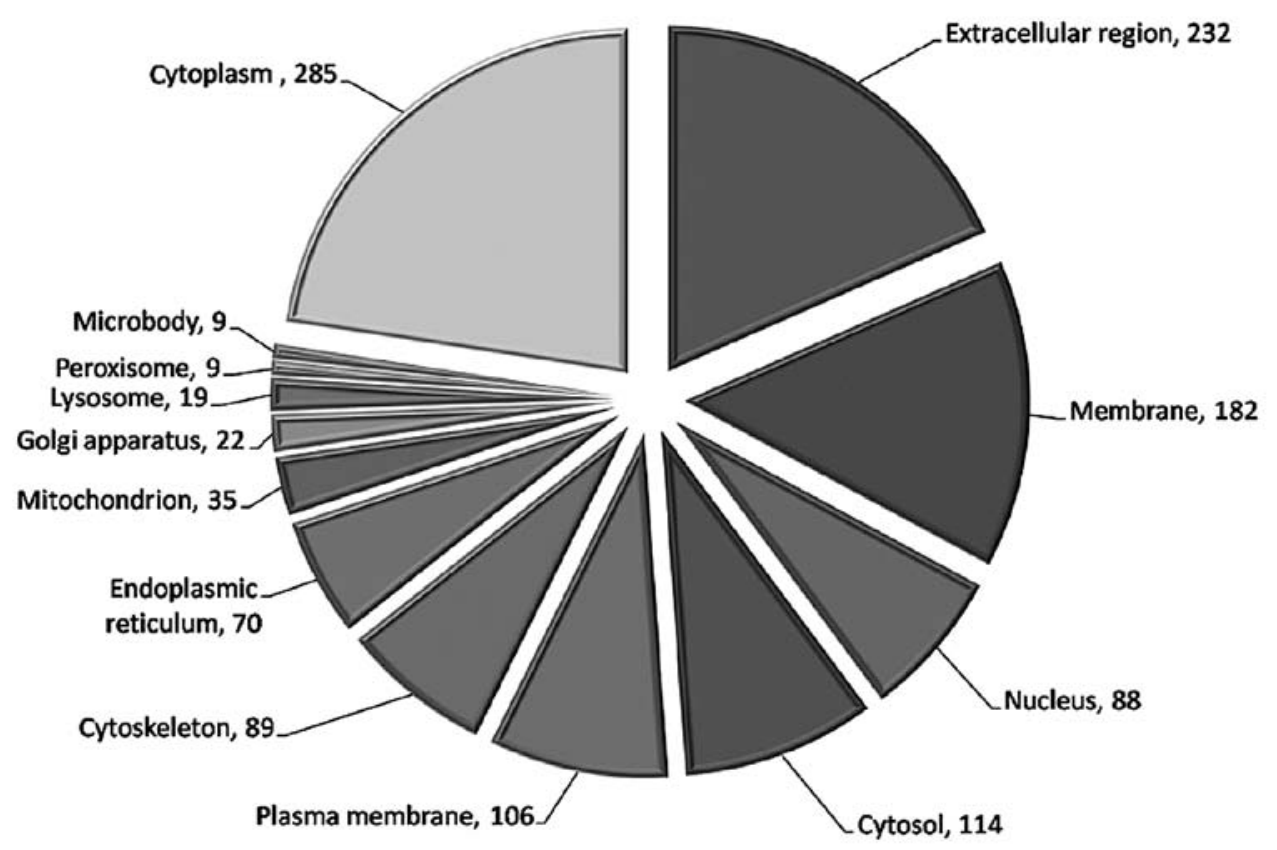

Figure 1. Subcellular localization of proteins in the conditioned medium (CM).

from Aviva Systems Biology (San Diego, CA, USA). Briefly, $100 \mu \mathrm{l}$ of diluted plasma was added to the wells of an anti-HPRT1 microplate, which was then incubated at $37^{\circ} \mathrm{C}$ for $2 \mathrm{~h}$. Subsequently, $100 \mu \mathrm{l}$ of prepared biotinylated HPRT1 detector antibody was added to each well, and the microplate was incubated at $37^{\circ} \mathrm{C}$ for $1 \mathrm{~h}$. After 3 washes, $100 \mu \mathrm{l}$ of prepared conjugate was added to each well, and the microplate was incubated at $37^{\circ} \mathrm{C}$ for $1 \mathrm{~h}$. After 5 washes, absorbance at $450 \mathrm{~nm}$ was immediately assessed using a microplate reader (Bio-Rad Laboratories, Hercules, CA, USA).

Statistical analysis. The relationships between plasma levels of the HPRT1 protein and clinical parameters were analyzed by he Mann-Whitney test, using SPSS software, version 17.0 (SPSS, Inc., Chicago, IL, USA). DFS and OS rates by plasma levels of the selected proteins were assessed by log-rank test, and the Kaplan-Meier curves. P-values $<0.05$ were considered statistically significant $(\mathrm{P}<0.05)$.

\section{Results}

Identification of free proteins in the CM of primary cultures of lung cancer and the corresponding control tissues Identification of proteins in the CM of primary cultures. For each case of lung cancer, the CM from the primary culture was dialyzed, lyophilized, bleached, reduced, alkylated and enzyme digested to obtain mixed peptides, which were then identified and sequenced using a nanoliter LC-MS/MS (LTQ, Thermo Finnigan). Among the CM samples corresponding to 9 cases (18 samples), a total of 987 high-confidence proteins (with at least two matching peptides for each protein) were detected (data not shown).

To further elucidate the biological significance of free proteins associated with lung cancer and the identified differential free proteins, we used the GO database to conduct biological functional classification for the 987 identified proteins. GO is an integrated classification system that can systematically annotate genes at three levels, molecular function, biological process and cellular component. As an important bioinformatic tool, GO can be used to identify common molecular and biological functions shared among a massive number of proteins.

Among the 987 proteins, $232(23.5 \%)$ are extracellular or secreted proteins, $182(18.4 \%)$ are membrane-associated proteins and the two types of proteins together account for $41.9 \%$ of all of the identified proteins (Fig. 1). This finding confirmed that this strategy was an effective method to enrich secreted proteins.

The 987 free proteins identified in the lung cancer microenvironment are primarily involved in such important processes as cell growth and maintenance, metabolism, catalysis, extracellular matrix (ECM)-receptor signaling transduction and cell adhesion. These proteins were enriched in 15 biological processes (Fig. 2), including protein binding, hydrolase activity, calcium ion binding and cytoskeletal protein binding.

Proteins involved in biological processes such as protein binding, hydrolase activity, calcium ion binding and cytoskeletal protein binding showed significantly elevated ratios in the CM, and those involved in biological processes such as nucleic acid binding, DNA binding and transferase activity demonstrated significantly reduced ratios in the CM.

Differential CM proteins identified by label-free quantitative proteomic technology. To improve the accuracy of the data, we used the standard of appearing in at least two samples to screen the 987 proteins and obtained 657 proteins of high confidence. On this basis, we used the spectral count produced by $\mathrm{MS} / \mathrm{MS}$ as the parameter and the total number of spectral counts produced by each LC-MS/MS identification for each sample as the benchmark to generate standardized data. 


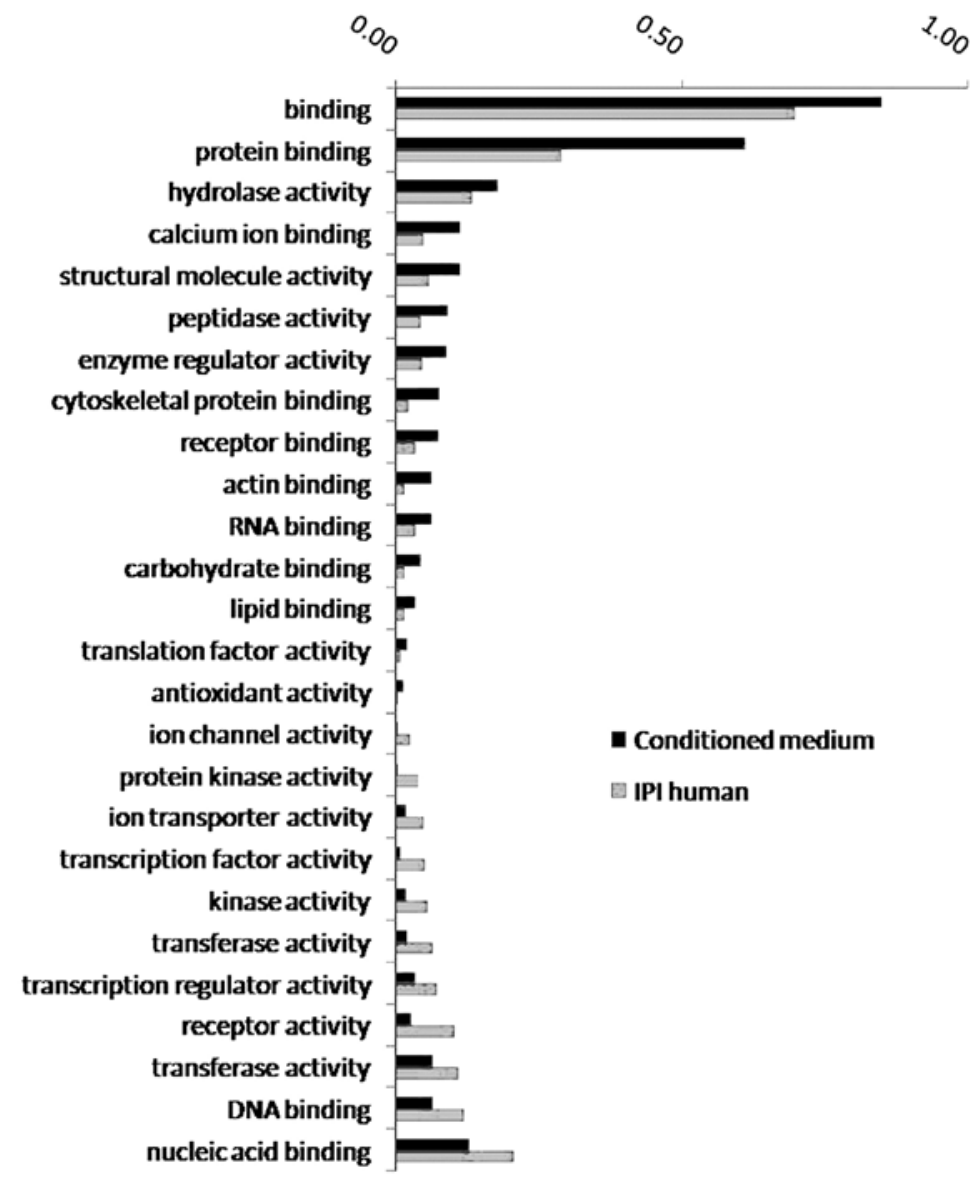

Figure 2. GO enrichment analysis of biological processes involving proteins in the CM. The proportion of proteins involved in 15 biological processes, such as protein binding, hydrolase activity, and other biological processes, increased significantly in the conditioned medium. The proportion of proteins involved in 11 biological processes, such as nucleic acid binding, DNA binding, and other biological processes, decreased significantly in the conditioned medium. GO, Gene Ontology; CM, conditioned medium.

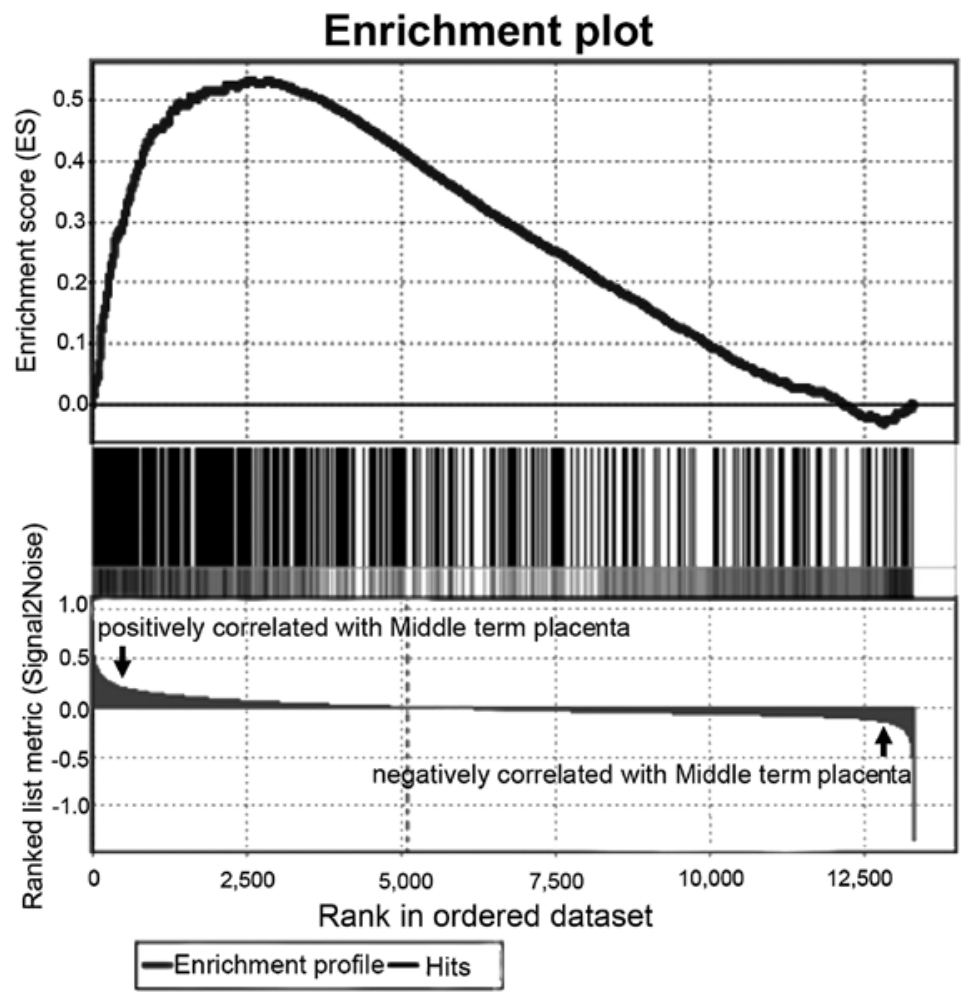

Figure 3. GSEA enrichment analysis of proteins in lung cancer tissue CM based on placental-maternal interface expression profiles at different stages. CM, conditioned medium. 
Table II. Seventy-eight proteins with increased expression in the CM of primary cultures of lung cancer.

\begin{tabular}{|c|c|c|c|c|}
\hline IPI accession no. & Gene symbol & Gene description & $\begin{array}{l}\text { Fold change } \\
\qquad(\mathrm{T} / \mathrm{N})\end{array}$ & Cover $(\%)$ \\
\hline IPI00012165.3 & MUC5B & Mucin 5B, oligomeric mucus/gel-forming & 16.59 & 0.47 \\
\hline IPI00031564.1 & C7orf24 & Chromosome 7 open reading frame 24 & 8.38 & 20.74 \\
\hline IPI00009943.2 & TPT1 & Tumor protein, translationally-controlled 1 & 5.49 & 15.43 \\
\hline IPI00171834.3 & KRT19 & Keratin 19 & 4.45 & 51.43 \\
\hline IPI00550640.2 & IGHG4 & & 4.27 & 15.64 \\
\hline IPI00024638.3 & LOC100133623 & & 4.18 & 17.03 \\
\hline IPI00549574.2 & OTUB1 & OTU domain, ubiquitin aldehyde binding 1 & 4.11 & 18.45 \\
\hline IPI00419384.1 & PRKCSH & Protein kinase $\mathrm{C}$ substrate $80 \mathrm{~K}-\mathrm{H}$ & 4.08 & 4.36 \\
\hline IPI00386327.1 & MUC5AC & Mucin 5AC, oligomeric mucus/gel-forming & 4.07 & 3.73 \\
\hline IPI00604523.1 & MRCL3 & Myosin regulatory light chain MRCL3 & 3.94 & 21.47 \\
\hline IPI00022792.3 & MFAP4 & Microfibrillar-associated protein 4 & 3.84 & 17.25 \\
\hline IPI00025110.3 & MSLN & Mesothelin & 3.65 & 15.92 \\
\hline IPI00477225.1 & PLS3 & Plastin 3 (T isoform) & 3.56 & 8.13 \\
\hline IPI00396378.3 & HNRNPA2B 1 & Heterogeneous nuclear ribonucleoprotein A2/B1 & 3.49 & 20.11 \\
\hline IPI00295386.6 & CBR1 & Carbonyl reductase 1 & 3.34 & 10.51 \\
\hline IPI00472610.2 & IGHM & & 3.14 & 21.34 \\
\hline IPI00100160.3 & CAND1 & Cullin-associated and neddylation-dissociated 1 & 3.03 & 14.15 \\
\hline IPI00215747.4 & FABP7 & Fatty acid binding protein 7 , brain & 3 & 63.36 \\
\hline IPI00012887.1 & CTSL1 & Cathepsin L1 & 2.97 & 10.51 \\
\hline IPI00027341.1 & CAPG & Capping protein (actin filament), gelsolin-like & 2.86 & 7.18 \\
\hline IPI00465248.4 & ENO1 & Enolase 1, (alpha) & 2.86 & 32.56 \\
\hline IPI00555616.1 & SOD2 & Superoxide dismutase 2 , mitochondrial & 2.81 & 19.37 \\
\hline IPI00001639.2 & KPNB1 & Karyopherin (importin) beta 1 & 2.78 & 9.36 \\
\hline IPI00514931.1 & THBS2 & Thrombospondin 2 & 2.69 & 9.47 \\
\hline IPI00478493.1 & HP & Haptoglobin & 2.67 & 14.78 \\
\hline IPI00219219.2 & LGALS1 & Lectin, galactoside-binding, soluble, 1 (galectin 1) & 2.65 & 23.13 \\
\hline IPI00552325.1 & HLA-C & Major histocompatibility complex, class I, C & 2.59 & 19.95 \\
\hline IPI00329200.4 & RANBP5 & RAN binding protein 5 & 2.55 & 8.68 \\
\hline IPI00012007.5 & AHCY & S-adenosylhomocysteine hydrolase & 2.53 & 17.40 \\
\hline IPI00013933.1 & DSP & Desmoplakin & 2.46 & 4.18 \\
\hline IPI00219018.5 & GAPDH & Glyceraldehyde-3-phosphate dehydrogenase & 2.45 & 22.09 \\
\hline IPI00216746.1 & HNRPK & Heterogeneous nuclear ribonucleoprotein $\mathrm{K}$ & 2.43 & 7.54 \\
\hline IPI00215911.2 & APEX1 & APEX nuclease (multifunctional DNA repair enzyme) 1 & 2.41 & 11.04 \\
\hline IPI00413112.2 & ANXA8 & Annexin A8 & 2.38 & 26.20 \\
\hline IPI00169383.2 & PGK1 & Phosphoglycerate kinase 1 & 2.36 & 20.91 \\
\hline IPI00383237.3 & PKM2 & Pyruvate kinase, muscle & 2.34 & 11.32 \\
\hline IPI00102821.3 & MGC29506 & Hypothetical protein MGC29506 & 2.31 & 28.04 \\
\hline IPI00105407.1 & AKR1B10 & Aldo-keto reductase family 1 , member B 10 (aldose reductase) & 2.3 & 49.05 \\
\hline IPI00031008.1 & TNC & Tenascin C (hexabrachion) & 2.3 & 24.35 \\
\hline IPI00186290.5 & EEF2 & Eukaryotic translation elongation factor 2 & 2.3 & 38.39 \\
\hline IPI00025512.2 & HSPB1 & Heat shock $27 \mathrm{kDa}$ protein 1 & 2.3 & 61.95 \\
\hline IPI00009342.1 & IQGAP1 & IQ motif containing GTPase activating protein 1 & 2.28 & 31.80 \\
\hline IPI00418262.3 & ALDOC & Aldolase $\mathrm{C}$, fructose-bisphosphate & 2.28 & 25.34 \\
\hline IPI00008527.1 & RPLP1 & Ribosomal protein, large, P1 & 2.24 & 51.75 \\
\hline IPI00479191.1 & HNRPH1 & Heterogeneous nuclear ribonucleoprotein $\mathrm{H} 1(\mathrm{H})$ & 2.21 & 11.65 \\
\hline IPI00019502.1 & MYH9 & Myosin, heavy chain 9, non-muscle & 2.21 & 11.33 \\
\hline IPI00215901.1 & AK2 & Adenylate kinase 2 & 2.21 & 28.03 \\
\hline IPI00216691.4 & PFN1 & Profilin 1 & 2.2 & 11.51 \\
\hline IPI00024466.1 & UGCGL1 & UDP-glucose ceramide glucosyltransferase-like 1 & 2.19 & 6.11 \\
\hline IPI00018352.1 & UCHL1 & Ubiquitin carboxyl-terminal esterase L1 (ubiquitin thiolesterase) & 2.13 & 38.57 \\
\hline IPI00024067.1 & CLTC & Clathrin, heavy chain $(\mathrm{Hc})$ & 2.13 & 10.81 \\
\hline
\end{tabular}


Table II. Continued.

\begin{tabular}{|c|c|c|c|c|}
\hline IPI accession no. & Gene symbol & Gene description & $\begin{array}{l}\text { Fold change } \\
\qquad(\mathrm{T} / \mathrm{N})\end{array}$ & Cover $(\%)$ \\
\hline IPI00028091.1 & ACTR3 & ARP3 actin-related protein 3 homolog (yeast) & 2.12 & 10.53 \\
\hline IPI00183626.7 & PTBP1 & Polypyrimidine tract binding protein 1 & 2.11 & 19.21 \\
\hline IPI00219525.9 & PGD & Phosphogluconate dehydrogenase & 2.09 & 15.56 \\
\hline IPI00382428.4 & FBLN5 & Fibulin 5 & 2.06 & 8.07 \\
\hline IPI00219025.2 & GLRX & Glutaredoxin (thioltransferase) & 2.06 & 11.43 \\
\hline IPI00216171.2 & ENO2 & Enolase 2 (gamma, neuronal) & 1.99 & 25.87 \\
\hline IPI00107831.3 & PTPRF & Protein tyrosine phosphatase, receptor type, F & 1.99 & 2.27 \\
\hline IPI00218836.1 & DBI & $\begin{array}{l}\text { Diazepam binding inhibitor (GABA receptor modulator, } \\
\text { acyl-Coenzyme A binding protein) }\end{array}$ & 1.99 & 34.62 \\
\hline IPI00465028.5 & TPI1 & Triosephosphate isomerase 1 & 1.98 & 42.17 \\
\hline IPI00399265.1 & TPD52L2 & Tumor protein D52-like 2 & 1.98 & 27.51 \\
\hline IPI00003881.3 & HNRPF & Heterogeneous nuclear ribonucleoprotein $\mathrm{F}$ & 1.96 & 20.00 \\
\hline IPI00060715.1 & KCTD12 & Potassium channel tetramerisation domain containing 12 & 1.95 & 15.08 \\
\hline IPI00000875.5 & EEF1G & Eukaryotic translation elongation factor 1 gamma & 1.94 & 16.28 \\
\hline IPI00465430.4 & XRCC6 & $\begin{array}{l}\text { X-ray repair complementing defective repair in Chinese hamster } \\
\text { cells } 6 \text { (Ku autoantigen, } 70 \mathrm{kDa})\end{array}$ & 1.92 & 10.18 \\
\hline IPI00514090.1 & LTA4H & Leukotriene A4 hydrolase & 1.91 & 25.93 \\
\hline IPI00010303.1 & SERPINB4 & Serpin peptidase inhibitor, clade B (ovalbumin), member 4 & 1.91 & 41.28 \\
\hline IPI00011937.1 & PRDX4 & Peroxiredoxin 4 & 1.9 & 9.23 \\
\hline IPI00550363.1 & TAGLN2 & Transgelin 2 & 1.89 & 25.63 \\
\hline IPI00008524.1 & PABPC1 & Poly(A) binding protein, cytoplasmic 1 & 1.89 & 13.68 \\
\hline IPI00005969.1 & CAPZA1 & Capping protein (actin filament) muscle Z-line, alpha 1 & 1.89 & 23.08 \\
\hline IPI00003269.1 & DKFZp686D0972 & Similar to RIKEN cDNA 4732495G21 gene & 1.87 & 16.49 \\
\hline IPI00395676.1 & UGP2 & UDP-glucose pyrophosphorylase 2 & 1.86 & 17.71 \\
\hline IPI00294578.1 & TGM2 & $\begin{array}{l}\text { Transglutaminase } 2 \text { (C polypeptide, } \\
\text { protein-glutamine-gamma-glutamyltransferase) }\end{array}$ & 1.86 & 10.19 \\
\hline IPI00020672.3 & DPP3 & Dipeptidyl-peptidase 3 & 1.83 & 10.05 \\
\hline IPI00479733.1 & ERO1L & ERO1-like (S. cerevisiae) & 1.78 & 13.86 \\
\hline IPI00007423.1 & ANP32B & $\begin{array}{l}\text { Acidic (leucine-rich) nuclear phosphoprotein } 32 \text { family, } \\
\text { member B }\end{array}$ & 1.76 & 20.32 \\
\hline IPI00023648.3 & ISLR & Immunoglobulin superfamily containing leucine-rich repeat & 1.62 & 7.01 \\
\hline
\end{tabular}

We used the standardized spectral counts of 18 samples as the relative quantitative parameters and used the Significance Analysis of Microarrays (SAM) algorithm to identify differential proteins between the CM from tumor tissues and the CM from paracancerous bronchial tissues. The data were randomly arranged, the calculations were performed 10,000 times and the results were corrected based on a false discovery rate (FDR) of 0.10 . We identified a total of 143 proteins that demonstrated significant differences. We calculated the ratios of the average spectral counts and all the differential proteins showed abundance changes $>1.5$ times. A total of 78 proteins showed significantly increased expression in the CM of the tumor tissue culture (Table II). These proteins included KRT19 (Cyfra21-1) and SERPINB4 (SCC), which are the lung cancer plasma markers currently used in clinical applications. A total of 65 proteins showed significantly decreased expression in the CM of the tumor tissue culture (Table III).
Exploration of proteins in the microenvironment associated with lung cancer invasion and metastasis from the perspective of developmental biology

Enrichment of the full spectrum of proteins in the lung cancer tissue culture CM in data from different stages of the placenta. Winn et al (12) used an Affy HG-U133A microarray and analyzed 36 placental-maternal interface specimens, including 9 specimens from placentas from full-term delivery and 27 specimens from second trimester placentas, leading to a set of differential gene expression profiles closely associated with placental invasion. In the present study, we identified 828 high-confidence proteins from the CM of the tissue culture corresponding to 9 cases of lung cancer, wherein 511 proteins were present for at least two cases and 427 proteins had corresponding gene IDs in the gene bank. We used the GSEA software to conduct enrichment analysis of the 427 proteins based on the differential gene expression profiles of specimens from the placental-maternal interface at different stages. The 
Table III. Sixty-five proteins with significantly decreased expression in the CM of the tumor tissue culture.

\begin{tabular}{|c|c|c|c|c|}
\hline IPI accession no. & Gene symbol & Gene description & $\begin{array}{l}\text { Fold change } \\
\qquad(\mathrm{T} / \mathrm{N})\end{array}$ & Cover $(\%)$ \\
\hline IPI00001508.1 & INS & Insulin precursor & 0.55 & 25.45 \\
\hline IPI00179357.1 & TTN & Titin & 0.54 & 0.08 \\
\hline IPI00299155.5 & PSMA4 & Proteasome subunit alpha type 4 & 0.53 & 17.62 \\
\hline IPI00020091.1 & ORM2 & Alpha-1-acid glycoprotein 2 precursor & 0.52 & 12.94 \\
\hline IPI00008164.1 & PREP & Prolyl endopeptidase & 0.50 & 4.93 \\
\hline IPI00401264.5 & TXNDC4 & Thioredoxin domain containing protein 4 precursor & 0.50 & 16.50 \\
\hline IPI00004656.1 & $\mathrm{B} 2 \mathrm{M}$ & Beta-2-microglobulin precursor & 0.50 & 26.89 \\
\hline IPI00006114.4 & SERPINF1 & Pigment epithelium-derived factor precursor & 0.49 & 15.31 \\
\hline IPI00293867.6 & DDT & D-dopachrome tautomerase & 0.48 & 17.95 \\
\hline IPI00292936.4 & CXCL5 & Small inducible cytokine B5 precursor & 0.46 & 10.53 \\
\hline IPI00298406.3 & HADH & 3-hydroxyacyl-CoA dehydrogenase, isoform 2 & 0.46 & 13.33 \\
\hline IPI00219682.5 & STOM & Erythrocyte band 7 integral membrane protein & 0.46 & 12.54 \\
\hline IPI00014572.1 & SPARC & SPARC precursor & 0.46 & 25.74 \\
\hline IPI00472112.1 & LOC730410 & $\begin{array}{l}\text { Splice Isoform } 2 \text { of HLA class I histocompatibility } \\
\text { antigen, A-11 alpha chain precursor }\end{array}$ & 0.45 & 8.36 \\
\hline IPI00024993.4 & ECHS1 & Enoyl-CoA hydratase, mitochondrial precursor & 0.45 & 19.31 \\
\hline IPI00556607.1 & PSMB4 & Proteasome (Prosome, macropain) subunit, beta type, 4 & 0.44 & 17.42 \\
\hline IPI00479877.3 & ALDH9A1 & 4-trimethylaminobutyraldehyde dehydrogenase & 0.44 & 5.67 \\
\hline IPI00003818.1 & KYNU & Kynureninase & 0.42 & 16.99 \\
\hline IPI00218323.1 & TPD52 & N8 protein long isoform & 0.42 & 10.08 \\
\hline IPI00012119.1 & $\mathrm{DCN}$ & Splice Isoform A of Decorin precursor & 0.41 & 20.61 \\
\hline IPI00295400.1 & WARS & Tryptophanyl-tRNA synthetase & 0.41 & 14.86 \\
\hline IPI00008561.1 & MMP1 & Interstitial collagenase precursor & 0.41 & 8.96 \\
\hline IPI00218163.1 & MUC1 & Splice Isoform 2 of Mucin-1 precursor & 0.40 & 2.22 \\
\hline IPI00219910.1 & BLVRB & Flavin reductase & 0.40 & 18.01 \\
\hline IPI00027463.1 & S100A6 & Calcyclin & 0.40 & 51.11 \\
\hline IPI00024284.4 & HSPG2 & $\begin{array}{l}\text { Basement membrane-specific heparan sulfate } \\
\text { proteoglycan core protein precursor }\end{array}$ & 0.40 & 3.83 \\
\hline IPI00395488.2 & VASN & Vasorin & 0.39 & 8.02 \\
\hline IPI00304840.3 & COL6A2 & Splice Isoform 2C2 of Collagen alpha 2(VI) chain precursor & 0.39 & 2.45 \\
\hline IPI00299738.1 & PCOLCE & Procollagen C-proteinase enhancer protein precursor & 0.38 & 4.68 \\
\hline IPI00413959.2 & CLSTN1 & Calsyntenin-1 precursor & 0.37 & 11.01 \\
\hline IPI00183508.2 & TWF1 & Twinfilin isoform 1 & 0.36 & 11.46 \\
\hline IPI00031030.1 & APLP2 & Splice Isoform 1 of Amyloid-like protein 2 precursor & 0.35 & 4.33 \\
\hline IPI00003590.1 & QSOX1 & Quiescin Q6 & 0.35 & 9.37 \\
\hline IPI00032293.1 & CST3 & Cystatin $\mathrm{C}$ precursor & 0.34 & 25.34 \\
\hline IPI00555841.1 & $\mathrm{H} 2 \mathrm{AFV}$ & $\mathrm{H} 2 \mathrm{~A}$ histone family, member $\mathrm{V}$ isoform 1 variant & 0.34 & 15.33 \\
\hline IPI00102165.1 & H2AFJ & Hypothetical protein FLJ10903 & 0.33 & 18.06 \\
\hline IPI00166866.3 & IGHV3OR16-13 & MGC27165 protein & 0.33 & 13.43 \\
\hline IPI00015102.1 & ALCAM & CD166 antigen precursor & 0.33 & 7.38 \\
\hline IPI00218816.6 & $\mathrm{HBB}$ & Hemoglobin beta chain & 0.32 & 87.76 \\
\hline IPI00007047.1 & S100A8 & Calgranulin A & 0.31 & 20.43 \\
\hline IPI00465260.1 & GARS & GARS protein & 0.31 & 4.79 \\
\hline IPI00026944.1 & NID1 & Nidogen precursor & 0.30 & 3.53 \\
\hline IPI00022078.3 & NDRG1 & NDRG1 protein & 0.30 & 20.56 \\
\hline IPI00216138.5 & TAGLN & Transgelin & 0.28 & 26.00 \\
\hline IPI00007427.1 & AGR2 & Anterior gradient protein 2 homolog precursor & 0.28 & 22.29 \\
\hline IPI00298237.4 & TPP1 & Splice Isoform 1 of Tripeptidyl-peptidase I precursor & 0.28 & 7.99 \\
\hline IPI00410714.2 & HBA1 & Alpha 2 globin variant & 0.25 & 30.28 \\
\hline IPI00305461.2 & ITIH2 & Inter-alpha-trypsin inhibitor heavy chain $\mathrm{H} 2$ precursor & 0.25 & 7.29 \\
\hline IPI00022463.1 & $\mathrm{TF}$ & Serotransferrin precursor & 0.25 & 13.47 \\
\hline
\end{tabular}


Table III. Continued.

\begin{tabular}{|c|c|c|c|c|}
\hline IPI accession no. & Gene symbol & Gene description & $\begin{array}{l}\text { Fold change } \\
\qquad(\mathrm{T} / \mathrm{N})\end{array}$ & Cover $(\%)$ \\
\hline IPI00299547.2 & LCN2 & Lipocalin 2 & 0.24 & 24.50 \\
\hline IPI00297646.2 & COL1A1 & AlphA 1 type I collAgen preproprotein & 0.24 & 2.80 \\
\hline IPI00020986.2 & LUM & Lumican precursor & 0.23 & 20.71 \\
\hline IPI00006663.1 & ALDH2 & Aldehyde dehydrogenase, mitochondrial precursor & 0.20 & 8.51 \\
\hline IPI00465084.5 & DES & Desmin & 0.19 & 14.71 \\
\hline IPI00029723.1 & FSTL1 & Follistatin-related protein 1 precursor & 0.16 & 11.36 \\
\hline IPI00027782.1 & MMP3 & Stromelysin-1 precursor & 0.15 & 12.58 \\
\hline IPI00216644.3 & GSTA1 & Glutathione S-transferase A1 & 0.15 & 48.87 \\
\hline IPI00400826.1 & CLU & Clusterin isoform 1 & 0.14 & 13.57 \\
\hline IPI00176193.5 & COL14A1 & Splice Isoform 1 of Collagen alpha 1(XIV) chain precursor & 0.14 & 7.41 \\
\hline IPI00025426.1 & $\mathrm{PZP}$ & Pregnancy zone protein precursor & 0.12 & 2.83 \\
\hline IPI00218414.4 & CA2 & Carbonic anhydrase II & 0.10 & 13.51 \\
\hline IPI00478003.1 & A2M & Alpha-2-macroglobulin precursor & 0.10 & 6.24 \\
\hline IPI00025465.1 & OGN & Mimecan precursor & 0.08 & 8.72 \\
\hline IPI00550991.1 & SERPINA3 & Alpha-1-antichymotrypsin precursor & 0.04 & 26.12 \\
\hline IPI00019038.1 & LYZ & Lysozyme $\mathrm{C}$ precursor & 0.03 & 31.08 \\
\hline
\end{tabular}
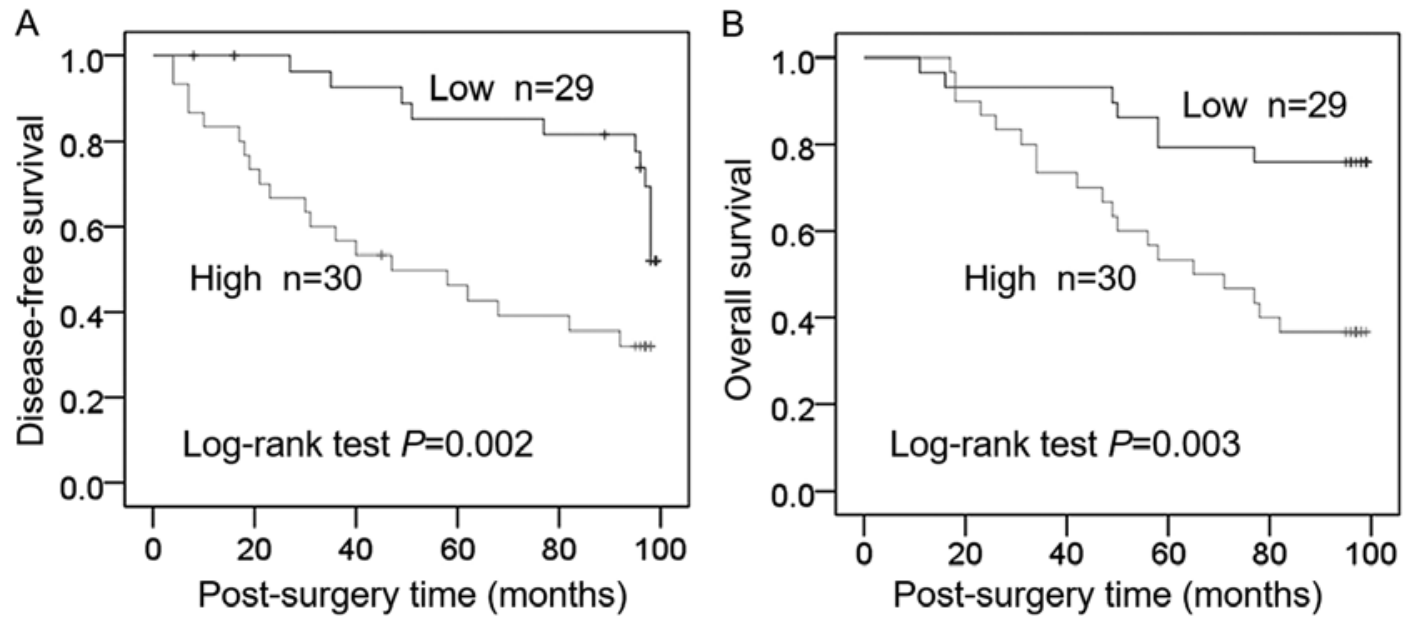

Figure 4. Kaplan-Meier curves indicating lower DFS and OS rates in patients with high HPRT1 ( $\mathrm{P}=0.002$ and $\mathrm{P}=0.003$, respectively). HPRT1, hypoxanthine phosphoribosyltransferase 1 .

results indicated that these free proteins had significant enrichment in the gene expression profile of the mid-term placenta of stronger invasiveness (Fig. 3), in which 197 proteins contributed significantly to the enrichment score (ES) $(\mathrm{P}=0.031$, Table IV).

HPRT1 exhibits the most significant enrichment among the 197 enriched proteins and is associated with worse DFS and OS. Hypoxanthine-guanine phosphoribosyltransferase (HPRT) is a housekeeping gene involved in nervous system development. HPRT deficiency causes the dysregulation of many cellular functions, including cell cycle control, proliferation, RNA metabolism, DNA replication and DNA repair (13). In the present study, HPRT1 exhibited the most significant enrichment among the 197 aforementioned proteins (Table IV).
Elevated plasma levels of HPRT1 protein were associated with poor prognosis. The median HPRT1 concentration $(0.50 \mathrm{ng} / \mathrm{ml})$ was defined as a cutoff point. The patients were divided into a low HPRT1 group $(n=29)$ and a high HPRT1 group $(n=30)$. Comparisons of Kaplan-Meier curves revealed lower DFS and OS among patients with high HPRT1 ( $\mathrm{P}=0.002$ and $\mathrm{P}=0.003$, respectively) (Fig. 4).

\section{Discussion}

In the present study, after a brief in vitro culture of lung cancer and normal bronchial tissues, we analyzed proteins that were released into serum-free CM (all ingredients are known). This system can accurately reflect the tumor microenvironment. 
Table IV. One hundred and ninety-seven free proteins enriched in tumor tissue CM based on the midterm maternal-placental interface expression profile.

\begin{tabular}{|c|c|c|c|}
\hline IPI accession no. & Gene symbol & Gene description & Cover $(\%)$ \\
\hline IPI00218914.4 & ALDH1A1 & Aldehyde dehydrogenase 1 family, member A1 & 6.40 \\
\hline IPI00021891.5 & FGG & Fibrinogen gamma chain & 7.88 \\
\hline IPI00297284.1 & IGFBP2 & Insulin-like growth factor binding protein $2,36 \mathrm{kDa}$ & 11.99 \\
\hline IPI00027341.1 & CAPG & Capping protein (actin filament), gelsolin-like & 7.18 \\
\hline IPI00027350.1 & PRDX2 & Peroxiredoxin 2 & 14.65 \\
\hline IPI00022200.2 & COL6A3 & Collagen, type VI, alpha 3 & 5.42 \\
\hline IPI00014230.1 & C1QBP & Complement component $1, \mathrm{q}$ subcomponent binding protein & 21.63 \\
\hline IPI00027780.1 & MMP2 & $\begin{array}{l}\text { Matrix metallopeptidase } 2 \text { (gelatinase A, } 72 \text { kDa gelatinase, } \\
72 \mathrm{kDa} \text { type IV collagenase) }\end{array}$ & 12.58 \\
\hline IPI00031420.1 & UGDH & UDP-glucose dehydrogenase & 8.70 \\
\hline IPI00028908.3 & NID2 & Nidogen 2 (osteonidogen) & 5.06 \\
\hline IPI00028564.1 & GBP1 & Guanylate binding protein 1 , interferon-inducible, $67 \mathrm{kDa}$ & 5.57 \\
\hline IPI00556478.1 & SH3BGRL & SH3 domain binding glutamic acid-rich protein like & 12.28 \\
\hline IPI00029658.1 & EFEMP1 & EGF-containing fibulin-like extracellular matrix protein 1 & 8.33 \\
\hline IPI00465248.4 & ENO1 & Enolase 1, (alpha) & 32.56 \\
\hline IPI00218493.6 & HPRT1 & Hypoxanthine phosphoribosyltransferase 1 (Lesch-Nyhan syndrome) & 24.42 \\
\hline IPI00009802.1 & VCAN & Versican & 1.39 \\
\hline IPI00219219.2 & LGALS1 & Lectin, galactoside-binding, soluble, 1 (galectin 1) & 23.13 \\
\hline IPI00411706.1 & ESD & Esterase D/formylglutathione hydrolase & 19.50 \\
\hline IPI00020986.2 & LUM & Lumican & 20.71 \\
\hline IPI00556088.1 & LGALS3 & Lectin, galactoside-binding, soluble, 3 & 15.66 \\
\hline IPI00550991.1 & SERPINA3 & $\begin{array}{l}\text { Serpin peptidase inhibitor, clade A (alpha- } 1 \text { antiproteinase, } \\
\text { antitrypsin), member } 3\end{array}$ & 26.12 \\
\hline IPI00219525.9 & PGD & Phosphogluconate dehydrogenase & 15.56 \\
\hline IPI00012119.1 & $\mathrm{DCN}$ & Decorin & 31.40 \\
\hline IPI00382428.4 & FBLN5 & Fibulin 5 & 8.07 \\
\hline IPI00027223.2 & IDH1 & Isocitrate dehydrogenase $1(\mathrm{NADP}+)$, soluble & 27.05 \\
\hline IPI00017601.1 & $\mathrm{CP}$ & Ceruloplasmin (ferroxidase) & 4.51 \\
\hline IPI00024284.4 & HSPG2 & Heparan sulfate proteoglycan 2 & 3.83 \\
\hline IPI00021000.1 & SPP1 & $\begin{array}{l}\text { Secreted phosphoprotein } 1 \text { (osteopontin, bone sialoprotein I, } \\
\text { early T-lymphocyte activation } 1 \text { ) }\end{array}$ & 19.18 \\
\hline IPI00400826.1 & CLU & CLU & 13.57 \\
\hline IPI00010133.1 & CORO1A & Coronin, actin binding protein, $1 \mathrm{~A}$ & 11.71 \\
\hline IPI00216298.5 & TXN & Thioredoxin & 32.94 \\
\hline IPI00220362.4 & HSPE1 & Heat shock $10 \mathrm{kDa}$ protein 1 (chaperonin 10 ) & 25.74 \\
\hline IPI00218836.1 & DBI & $\begin{array}{l}\text { Diazepam binding inhibitor (GABA receptor modulator, } \\
\text { acyl-Coenzyme A binding protein) }\end{array}$ & 34.62 \\
\hline IPI00017696.1 & $\mathrm{C} 1 \mathrm{~S}$ & Complement component 1 , s subcomponent & 5.06 \\
\hline IPI00028091.1 & ACTR3 & ARP3 actin-related protein 3 homolog (yeast) & 10.53 \\
\hline IPI00026199.1 & GPX3 & Glutathione peroxidase 3 (plasma) & 13.72 \\
\hline IPI00295741.3 & CTSB & Cathepsin B & 9.14 \\
\hline IPI00011937.1 & PRDX4 & Peroxiredoxin 4 & 9.23 \\
\hline IPI00021841.1 & APOA1 & Apolipoprotein A-I & 15.73 \\
\hline IPI00024095.2 & ANXA3 & Annexin A3 & 36.34 \\
\hline IPI00001699.1 & PYCARD & PYD and CARD domain containing & 22.46 \\
\hline IPI00301579.3 & NPC2 & Niemann-Pick disease, type C2 & 25.83 \\
\hline IPI00021033.1 & COL3A1 & $\begin{array}{l}\text { Collagen, type III, alpha } 1 \text { (Ehlers-Danlos syndrome type IV, } \\
\text { autosomal dominant) }\end{array}$ & 6.71 \\
\hline IPI00027497.4 & GPI & Glucose phosphate isomerase & 5.75 \\
\hline IPI00021842.1 & APOE & Apolipoprotein E & 17.35 \\
\hline IPI00215911.2 & APEX1 & APEX nuclease (multifunctional DNA repair enzyme) 1 & 11.04 \\
\hline
\end{tabular}


Table IV. Continued.

\begin{tabular}{|c|c|c|c|}
\hline IPI accession no. & Gene symbol & Gene description & Cover $(\%)$ \\
\hline IPI00018219.1 & TGFBI & Transforming growth factor, beta-induced, $68 \mathrm{kDa}$ & 18.89 \\
\hline IPI00027444.1 & SERPINB1 & Serpin peptidase inhibitor, clade B (ovalbumin), member 1 & 15.57 \\
\hline IPI00216134.2 & TPM1 & Tropomyosin 1 (alpha) & 13.03 \\
\hline IPI00018146.1 & YWHAQ & $\begin{array}{l}\text { Tyrosine } 3 \text {-monooxygenase/tryptophan 5-monooxygenase } \\
\text { activation protein, theta polypeptide }\end{array}$ & 10.61 \\
\hline IPI00021828.1 & CSTB & Cystatin B (stefin B) & 12.24 \\
\hline IPI00017292.1 & CTNNB1 & Catenin (cadherin-associated protein), beta $1,88 \mathrm{kDa}$ & 6.27 \\
\hline IPI00032292.1 & TIMP1 & TIMP metallopeptidase inhibitor 1 & 17.87 \\
\hline IPI00022810.1 & CTSC & Cathepsin C & 7.56 \\
\hline IPI00176903.2 & PTRF & Polymerase I and transcript release factor & 11.67 \\
\hline IPI00217966.5 & LDHA & Lactate dehydrogenase A & 30.42 \\
\hline IPI00011229.1 & CTSD & Cathepsin D & 5.83 \\
\hline IPI00304692.1 & RBMX & RNA binding motif protein, $\mathrm{X}$-linked & 6.91 \\
\hline IPI00397526.1 & MYH10 & Myosin, heavy chain 10, non-muscle & 2.99 \\
\hline IPI00465038.2 & FBLN2 & Fibulin 2 & 3.09 \\
\hline IPI00465315.5 & CYCS & Cytochrome c, somatic & 19.23 \\
\hline IPI00019755.3 & GSTO1 & Glutathione S-transferase omega 1 & 32.22 \\
\hline IPI00003817.1 & ARHGDIB & Rho GDP dissociation inhibitor (GDI) beta & 15.42 \\
\hline IPI00005161.3 & ARPC2 & Actin related protein $2 / 3$ complex, subunit $2,34 \mathrm{kDa}$ & 16.00 \\
\hline IPI00011654.2 & TUBB & Tubulin, beta & 38.51 \\
\hline IPI00553177.1 & SERPINA1 & $\begin{array}{l}\text { Serpin peptidase inhibitor, clade A (alpha-1 antiproteinase, } \\
\text { antitrypsin), member } 1\end{array}$ & 7.66 \\
\hline IPI00031812.1 & YBX1 & Y box binding protein 1 & 11.18 \\
\hline IPI00555616.1 & SOD2 & Superoxide dismutase 2 , mitochondrial & 19.37 \\
\hline IPI00023673.1 & LGALS3BP & Lectin, galactoside-binding, soluble, 3 binding protein & 10.60 \\
\hline IPI00302592.1 & FLNA & Filamin A, alpha (actin binding protein 280) & 5.25 \\
\hline IPI00216691.4 & PFN1 & Profilin 1 & 11.51 \\
\hline IPI00009904.1 & PDIA4 & Protein disulfide isomerase family A, member 4 & 8.22 \\
\hline IPI00299547.2 & LCN2 & Lipocalin 2 (oncogene $24 \mathrm{p} 3)$ & 24.50 \\
\hline IPI00219217.2 & LDHB & Lactate dehydrogenase B & 21.02 \\
\hline IPI00433214.1 & CKAP4 & Cytoskeleton-associated protein 4 & 6.70 \\
\hline IPI00006114.4 & SERPINF1 & $\begin{array}{l}\text { Serpin peptidase inhibitor, clade } \mathrm{F} \text { (alpha- } 2 \text { antiplasmin, pigment } \\
\text { epithelium derived factor), member } 1\end{array}$ & 15.31 \\
\hline IPI00220301.4 & PRDX6 & Peroxiredoxin 6 & 49.78 \\
\hline IPI00013079.1 & EMILIN1 & Elastin microfibril interfacer 1 & 5.71 \\
\hline IPI00329633.5 & TARS & Threonyl-tRNA synthetase & 8.02 \\
\hline IPI00022733.1 & PLTP & Phospholipid transfer protein & 18.14 \\
\hline IPI00477225.1 & PLS3 & Plastin 3 ( $\mathrm{T}$ isoform) & 8.10 \\
\hline IPI00375676.2 & FTL & Ferritin, light polypeptide & 13.39 \\
\hline IPI00015361.1 & PFDN5 & Prefoldin subunit 5 & 33.77 \\
\hline IPI00013508.3 & ACTN1 & Actinin, alpha 1 & 13.68 \\
\hline IPI00472102.1 & HSPD1 & Heat shock 60 kDa protein 1 (chaperonin) & - \\
\hline IPI00220271.2 & AKR1A1 & Aldo-keto reductase family 1, member A1 (aldehyde reductase) & 23.15 \\
\hline IPI00024993.4 & ECHS 1 & Enoyl Coenzyme A hydratase, short chain, 1, mitochondrial & 19.31 \\
\hline IPI00307162.2 & VCL & Vinculin & 23.02 \\
\hline IPI00419237.1 & LAP3 & Leucine aminopeptidase 3 & 13.10 \\
\hline IPI00022434.2 & ALB & Albumin & 44.84 \\
\hline IPI00029260.2 & CD14 & CD14 molecule & 30.67 \\
\hline IPI00298406.3 & HADH & Hydroxyacyl-Coenzyme A dehydrogenase & 13.33 \\
\hline IPI00219018.5 & GAPDH & Glyceraldehyde-3-phosphate dehydrogenase & 22.09 \\
\hline IPI00013976.1 & LAMB1 & Laminin, beta 1 & 7.78 \\
\hline IPI00554634.1 & CUTA & CutA divalent cation tolerance homolog (E. coli) & 32.96 \\
\hline
\end{tabular}


Table IV. Continued.

\begin{tabular}{|c|c|c|c|}
\hline IPI accession no. & Gene symbol & Gene description & Cover $(\%)$ \\
\hline IPI00028004.2 & PSMB3 & Proteasome (prosome, macropain) subunit, beta type, 3 & 16.59 \\
\hline IPI00289334.1 & FLNB & Filamin B, beta (actin binding protein 278 ) & 14.24 \\
\hline IPI00025084.2 & CAPNS1 & Calpain, small subunit 1 & 11.80 \\
\hline IPI00219446.4 & PEBP1 & Phosphatidylethanolamine binding protein 1 & 15.59 \\
\hline IPI00020672.3 & DPP3 & Dipeptidyl-peptidase 3 & 10.05 \\
\hline IPI00514377.3 & HSPA1A & Heat shock $70 \mathrm{kDa}$ protein $1 \mathrm{~A}$ & 15.29 \\
\hline IPI00003815.1 & ARHGDIA & Rho GDP dissociation inhibitor (GDI) alpha & 38.24 \\
\hline IPI00514090.1 & LTA4H & Leukotriene A4 hydrolase & 25.93 \\
\hline IPI00005159.2 & ACTR2 & ARP2 actin-related protein 2 homolog (yeast) & 18.05 \\
\hline IPI00007853.1 & IFI30 & Interferon, gamma-inducible protein 30 & 32.18 \\
\hline IPI00032140.2 & SERPINH1 & $\begin{array}{l}\text { Serpin peptidase inhibitor, clade } \mathrm{H} \text { (heat shock protein } 47 \text { ), } \\
\text { member } 1 \text {, (collagen binding protein } 1 \text { ) }\end{array}$ & 33.73 \\
\hline IPI00012726.3 & PABPC4 & Poly(A) binding protein, cytoplasmic 4 (inducible form) & 6.97 \\
\hline IPI00027933.1 & PSMB10 & Proteasome (prosome, macropain) subunit, beta type, 10 & 19.05 \\
\hline IPI00419258.3 & HMGB 1 & High-mobility group box 1 & 16.36 \\
\hline IPI00298497.3 & FGB & Fibrinogen beta chain & 6.11 \\
\hline IPI00003590.1 & QSOX1 & Quiescin Q6 sulfhydryl oxidase 1 & 11.59 \\
\hline IPI00183695.6 & S100A10 & S100 calcium binding protein A10 & 40.62 \\
\hline IPI00554482.1 & NPM1 & Nucleophosmin (nucleolar phosphoprotein B23, numatrin) & 11.41 \\
\hline IPI00017672.2 & NP & Nucleoside phosphorylase & 53.58 \\
\hline IPI00180675.4 & TUBA1A & Tubulin, alpha 1a & 7.76 \\
\hline IPI00026781.2 & FASN & Fatty acid synthase & 4.90 \\
\hline IPI00329200.4 & RANBP5 & RAN binding protein 5 & - \\
\hline IPI00465260.1 & GARS & Glycyl-tRNA synthetase & 4.79 \\
\hline IPI00550073.1 & CALM3 & Calmodulin 3 (phosphorylase kinase, delta) & 22.45 \\
\hline IPI00376005.1 & EIF5A & Eukaryotic translation initiation factor $5 \mathrm{~A}$ & 23.53 \\
\hline IPI00219622.2 & PSMA2 & Proteasome (prosome, macropain) subunit, alpha type, 2 & 17.60 \\
\hline IPI00005087.1 & TMOD3 & Tropomodulin 3 (ubiquitous) & 16.19 \\
\hline IPI00419262.1 & PPIB & Peptidylprolyl isomerase B (cyclophilin B) & - \\
\hline IPI00290279.1 & ADK & Adenosine kinase & 13.81 \\
\hline IPI00007427.1 & AGR2 & Anterior gradient homolog 2 (Xenopus laevis) & 22.29 \\
\hline IPI00413451.1 & SERPINB6 & Serpin peptidase inhibitor, clade B (ovalbumin, member 6 & 20.00 \\
\hline IPI00031461.1 & GDI2 & GDP dissociation inhibitor 2 & 8.54 \\
\hline IPI00028931.1 & DSG2 & Desmoglein 2 & 3.13 \\
\hline IPI00026216.4 & NPEPPS & Aminopeptidase puromycin sensitive & 6.42 \\
\hline IPI00550363.1 & TAGLN2 & Transgelin 2 & 25.63 \\
\hline IPI00418262.3 & ALDOC & Aldolase $\mathrm{C}$, fructose-bisphosphate & 25.34 \\
\hline IPI00008527.1 & RPLP1 & Ribosomal protein, large, P1 & 51.75 \\
\hline IPI00299155.5 & PSMA4 & Proteasome (prosome, macropain) subunit, alpha type, 4 & 17.62 \\
\hline IPI00479786.1 & KHSRP & KH-type splicing regulatory protein (FUSE binding protein 2) & 4.37 \\
\hline IPI00303318.2 & FAM49B & Family with sequence similarity 49, member B & 28.70 \\
\hline IPI00555900.1 & FKSG30 & Kappa-actin & 12.00 \\
\hline IPI00176193.5 & COL14A1 & Collagen, type XIV, alpha 1 (undulin) & 7.47 \\
\hline IPI00413959.2 & CLSTN1 & Calsyntenin 1 & 11.01 \\
\hline IPI00021440.1 & ACTG1 & Actin, gamma 1 & 17.60 \\
\hline IPI00556607.1 & PSMB4 & Proteasome (prosome, macropain) subunit, beta type, 4 & 17.42 \\
\hline IPI00025861.2 & CDH1 & Cadherin 1, type 1, E-cadherin (epithelial) & 9.10 \\
\hline IPI00220644.6 & PKM2 & Pyruvate kinase, muscle & 14.75 \\
\hline IPI00257882.5 & PEPD & Peptidase D & 11.76 \\
\hline IPI00106642.4 & SDF2L1 & Stromal cell-derived factor 2 -like 1 & 6.46 \\
\hline IPI00013698.1 & ASAH1 & $\mathrm{N}$-acylsphingosine amidohydrolase (acid ceramidase) 1 & 9.25 \\
\hline IPI00032293.1 & CST3 & Cystatin C (amyloid angiopathy and cerebral hemorrhage) & 25.34 \\
\hline
\end{tabular}


Table IV. Continued.

\begin{tabular}{|c|c|c|c|}
\hline IPI accession no. & Gene symbol & Gene description & Cover $(\%)$ \\
\hline IPI00298281.3 & LAMC1 & Laminin, gamma 1 (formerly LAMB2) & 5.97 \\
\hline IPI00026185.4 & CAPZB & Capping protein (actin filament) muscle Z-line, beta & 24.25 \\
\hline IPI00298547.3 & PARK7 & Parkinson disease (autosomal recessive, early onset) 7 & 30.16 \\
\hline IPI00297646.2 & COL1A1 & Collagen, type I, alpha 1 & 2.80 \\
\hline IPI00298853.5 & GC & Group-specific component (vitamin D binding protein) & 22.36 \\
\hline IPI00553185.2 & ССТ3 & Chaperonin containing TCP1, subunit 3 (gamma) & 11.38 \\
\hline IPI00292771.3 & NUMA1 & Nuclear mitotic apparatus protein 1 & 1.80 \\
\hline IPI00293867.6 & DDT & D-dopachrome tautomerase & 17.95 \\
\hline IPI00008561.1 & MMP1 & Matrix metallopeptidase 1 (interstitial collagenase) & 8.96 \\
\hline IPI00298994.3 & TLN1 & Talin 1 & 1.65 \\
\hline IPI00002460.2 & ANXA7 & Annexin A7 & 9.02 \\
\hline IPI00297550.7 & F13A1 & Coagulation factor XIII, A1 polypeptide & 6.16 \\
\hline IPI00465439.4 & ALDOA & Aldolase A, fructose-bisphosphate & 7.16 \\
\hline IPI00004656.1 & B2M & Beta-2-microglobulin & 26.89 \\
\hline IPI00216318.4 & YWHAB & $\begin{array}{l}\text { Tyrosine } 3 \text {-monooxygenase/tryptophan } 5 \text {-monooxygenase activation } \\
\text { protein, beta polypeptide }\end{array}$ & 20.00 \\
\hline IPI00296534.1 & FBLN1 & Fibulin 1 & 14.20 \\
\hline IPI00003818.1 & KYNU & Kynureninase (L-kynurenine hydrolase) & 16.99 \\
\hline IPI00008223.3 & RAD23B & RAD23 homolog B (S. cerevisiae) & 7.33 \\
\hline IPI00440493.2 & ATP5A1 & $\begin{array}{l}\text { ATP synthase, } \mathrm{H}+\text { transporting, mitochondrial } \mathrm{F} 1 \text { complex, } \\
\text { alpha subunit } 1, \text { cardiac muscle }\end{array}$ & 5.42 \\
\hline IPI00219445.1 & PSME3 & $\begin{array}{l}\text { Proteasome (prosome, macropain) activator subunit } 3 \\
\text { (PA28 gamma; Ki) }\end{array}$ & 16.48 \\
\hline IPI00016862.1 & GSR & Glutathione reductase & 12.26 \\
\hline IPI00220991.2 & AP2B1 & Adaptor-related protein complex 2 , beta 1 subunit & - \\
\hline IPI00215965.1 & HNRNPA1 & Heterogeneous nuclear ribonucleoprotein A1 & 11.88 \\
\hline IPI00010740.1 & SFPQ & $\begin{array}{l}\text { Splicing factor proline/glutamine-rich (polypyrimidine } \\
\text { tract binding protein associated) }\end{array}$ & 5.08 \\
\hline IPI00027626.2 & СCT6А & Chaperonin containing TCP1, subunit 6A (zeta 1) & 6.42 \\
\hline IPI00398779.3 & PLEC1 & Plectin 1, intermediate filament binding protein $500 \mathrm{kDa}$ & 0.49 \\
\hline IPI00027463.1 & S100A6 & S100 calcium binding protein A6 & 51.11 \\
\hline IPI00026087.1 & BANF1 & Barrier to autointegration factor 1 & 29.21 \\
\hline IPI00305969.1 & EEF1D & $\begin{array}{l}\text { Eukaryotic translation elongation factor } 1 \text { delta } \\
\text { (guanine nucleotide exchange protein) }\end{array}$ & 4.35 \\
\hline IPI00177728.3 & CNDP2 & CNDP dipeptidase 2 (metallopeptidase M20 family) & 26.53 \\
\hline IPI00021347.1 & UBE2L3 & Ubiquitin-conjugating enzyme E2L 3 & 21.43 \\
\hline IPI00414676.5 & HSP90AB1 & Heat shock protein $90 \mathrm{kDa}$ alpha (cytosolic), class B member 1 & 7.33 \\
\hline IPI00216319.2 & YWHAH & $\begin{array}{l}\text { Tyrosine 3-monooxygenase/tryptophan 5-monooxygenase activation } \\
\text { protein, eta polypeptide }\end{array}$ & 11.84 \\
\hline IPI00013890.1 & SFN & Stratifin & 41.53 \\
\hline IPI00556148.1 & $\mathrm{CFH}$ & Complement factor $\mathrm{H}$ & 4.14 \\
\hline IPI00329801.10 & ANXA5 & Annexin A5 & 40.62 \\
\hline IPI00455315.3 & ANXA2 & Annexin A2 & 48.52 \\
\hline IPI00009771.4 & LMNB2 & Lamin B2 & 4.33 \\
\hline IPI00299000.1 & PA2G4 & Proliferation-associated 2G4, $38 \mathrm{kDa}$ & 16.24 \\
\hline IPI00297779.6 & ССТ2 & Chaperonin containing TCP1, subunit 2 (beta) & 13.67 \\
\hline IPI00168184.5 & PPP2R1A & $\begin{array}{l}\text { Protein phosphatase } 2 \text { (formerly } 2 \mathrm{~A} \text { ), regulatorysubunit } \mathrm{A} \text {, } \\
\text { alpha isoform }\end{array}$ & 12.93 \\
\hline IPI00012074.2 & HNRNPR & Heterogeneous nuclear ribonucleoprotein $\mathrm{R}$ & 4.40 \\
\hline IPI00018768.1 & TSN & Translin & 27.19 \\
\hline IPI00005614.4 & SPTBN1 & Spectrin, beta, non-erythrocytic 1 & 10.77 \\
\hline IPI00008524.1 & PABPC1 & Poly (A) binding protein, cytoplasmic 1 & 15.90 \\
\hline
\end{tabular}


Table IV. Continued.

\begin{tabular}{|c|c|c|c|}
\hline IPI accession no. & Gene symbol & Gene description & Cover $(\%)$ \\
\hline IPI00013895.1 & S100A11 & S100 calcium binding protein A11 & 56.19 \\
\hline IPI00010796.1 & P4HB & $\begin{array}{l}\text { Procollagen-proline, 2-oxoglutarate 4-dioxygenase } \\
\text { (proline 4-hydroxylase), beta polypeptide }\end{array}$ & 18.31 \\
\hline IPI00100160.3 & CAND1 & Cullin-associated and neddylation-dissociated 1 & 16.38 \\
\hline IPI00007752.1 & TUBB2C & Tubulin, beta $2 \mathrm{C}$ & 45.17 \\
\hline IPI00007118.1 & SERPINE1 & $\begin{array}{l}\text { Serpin peptidase inhibitor, clade } \mathrm{E} \text { (nexin, plasminogen activator } \\
\text { inhibitor type 1), member } 1\end{array}$ & 23.38 \\
\hline IPI00451401.2 & TPI1 & Triosephosphate isomerase 1 & 42.17 \\
\hline
\end{tabular}

We used LTQ MS with the characteristics of high scanning speed to identify the full spectrum of the total protein in CM samples and completed the initial establishment of a lung cancer-associated free protein database. The primary organ culture model eliminates the interference from high-abundance proteins, reduces the dynamic range of the full spectrum of proteins, and is suitable for label-free quantitative proteomics. Therefore, we introduced a label-free quantitative parameter, spectral count, to identify differential free proteins in the $\mathrm{CM}$ while obtaining the full spectrum of proteins. The use of biostatistics and bioinformatics enables us to standardize MS data, identify differential proteins and establish differential protein profiles that can correctly distinguish cancer and paracancerous normal tissues. We used protein annotation, as well as GO, network and pathway analysis, to investigate the signaling pathways underlying changes in free proteins in the lung cancer microenvironment.

In the present study, the proteins in the lung cancer $\mathrm{CM}$ were significantly enriched in gene clusters associated with the midterm maternal-placental interface of strong invasiveness. Similar to the trophoblast cell-mediated invasion that occurs in the maternal-placental interface, tumor invasion occurs at the boundary where the tumor and host interact, and the exchange of cytokines and related proteases between tumor cells and stromal cells further facilitates tumor cell migration (14). We identified that the full spectrum of tumor tissue CM likely reflects the dynamic change in this microenvironment. It is noteworthy that compared with the heterogeneity and multiple genetic changes in tumor occurrence and development, the individual difference in embryonic development is much smaller. It may be possible to simplify the interpretation of tumor invasion from the perspective of developmental biology.

Since Lobstein et al introduced the concept of the embryonic origin of tumors in 1829, the similarities in biological behaviors between embryo implantation and tumor invasion/metastasis have received increasing attention. Embryo implantation is under the complex regulatory network involving hormones, cytokines, the immune system and genes, and implantation is a precise physiological process with strict temporal and spatial regulation, whereas invasion is a malignant pathological life phenomenon of malignancies with deregulated temporal and spatial control. During the embryonic implantation process, 'false malignant' trophoblast cells of blastocysts show striking similarities with cancer cells in terms of cell proliferation and differentiation, signal transduction pathways for invasion, vascular erosion and angiogenesis, immune escape and apoptosis (15). Research on embryo implantations has revealed that during the process of embryonic implantation into the endometrium, a large number of oncogenes are expressed that are also expressed during the process of tumor formation. These oncogenes include c-Met, c-fms, c-Ki, FGF-2 and Src (15). Numerous studies have revealed that matrix metalloproteinases (MMPs), the ECM and numerous cell adhesion molecules are also involved in the implantation of early embryonic trophoblast cells into the endometrium and in the process of tumor invasion and metastasis $(17,18)$.

Winn et al (12) used chips to analyze placental-maternal interface specimens and obtained differential gene expression profiles that were closely associated with placental invasion. We identified a total of 828 high-confidence proteins in the $\mathrm{CM}$ from the tumor tissue culture corresponding to 9 cases of lung cancer, wherein 511 proteins were present for at least two cases, and 427 proteins had corresponding gene IDs in the gene bank. We used the GSEA software to conduct enrichment analysis of the 427 proteins based on the differential expression profiles of placental-maternal interfaces at different stages. The results indicated that 197 free proteins had significant enrichment in the gene expression profiles of the midterm placenta. We also performed a further in-depth study of the SPP1, TIMP-1 and YWHAB expression in NSCLC. Using the lung cancer tissue microarray constructed in our laboratory, we assessed the expression of these proteins for samples corresponding to 318 cases of NSCLC. The results revealed that the expression levels of SPP1 (19), TIMP-1 and YWHAB (20) in lung tumor tissues and lymph node metastatic foci were significantly higher than those in normal lung tissues and the expression of these proteins was correlated to lymph node metastasis and clinical stage. In addition, overexpression of SPP1 promoted ECM invasion by lung cancer cells.

HPRT1 exhibited the most significant enrichment among the 197 significantly enriched proteins and was associated with worse DFS and OS for the lung cancer patients included in the present study. Several studies have demonstrated that HPRT1 mutations are associated with the exposure of lung epithelial cells to particles, which induces massive neutrophil recruitment and is correlated with tumor formation $(21,22)$. The in vitro coincubation of rat lung epithelial cells with bronchoalveolar lavage (BAL) cells isolated from 
particle-treated rats increased mutation frequency in the HPRT gene (23). The downregulation of etoposide-induced p38 mitogen-activated protein kinase (MAPK)-mediated expression of excision repair cross-complementary 1 (ERCC1) could reduce significant increases in etoposide-induced HPRT gene mutation frequency and decrease the cellular ability to repair DNA damage in etoposide-exposed human NSCLC cells (24). In secondhand smoke research, human lung cancer cells exposed to sidestream smoke for $24 \mathrm{~h}$ exhibited significantly elevated levels of oxidative DNA damage to HPRT, which contributed to lung carcinogenesis (25).

In conclusion, embryonic development and tumor formation demonstrate similar behaviors and underlying molecular mechanisms, and tumors can be considered a special 'organ' due to an abnormal regulation of organ formation (26). Accordingly, the present study investigated lung cancer based on an embryonic development model and combined systems biology and developmental biology to simplify the tumor analysis model and thus identify the protein profiles associated with lung cancer invasion and metastasis.

\section{Acknowledgements}

The authors thank Professor Wantao Ying and Dr Wei Jia, for their technical support of LC-MS analysis.

\section{Funding}

The present study was funded by the CAMS Innovation Fund for Medical Sciences (CIFMS) (grant no. 2016-I2 M-1-001) and the National Basic Research Program of China (grant no. 2014CBA02004).

\section{Availability of data and materials}

The datasets used during the present study are available from the corresponding author upon reasonable request.

\section{Authors' contributions}

LF and TX conceived and designed the study. LF, YY, ML and JS performed the experiments. TX and ML wrote the paper. LF, YG, JS and SC reviewed and edited the manuscript and were also involved in the conception of this study. All authors read and approved the manuscript and agree to be accountable for all aspects of the research in ensuring that the accuracy or integrity of any part of the work are appropriately investigated and resolved.

\section{Ethics approval and consent to participate}

All patients provided written informed consent before surgery, and treatments were performed in accordance with current ethical principles of the Independent Ethics Committee, Cancer Hospital, Chinese Academy of Medical Sciences.

\section{Patient consent for publication}

Not applicable.

\section{Competing interests}

The authors state that they have no competing interests.

\section{References}

1. Siegel RL, Miller KD and Jemal A: Cancer statistics, 2015. CA Cancer J Clin 64: 5-29, 2015.

2. Torre LA, Bray F, Siegel RL, Ferlay J, Lortet-Tieulent J and Jemal A: Global cancer statistics, 2012. CA Cancer J Clin 65: 87-108, 2015.

3. Krebs ET: Cancer and the embryonal hypothesis. Calif Med 66: 270-271, 1947.

4. Pierce GB: The cancer cell and its control by the embryo. Rous-Whipple Award lecture. Am J Pathol 113: 117-124, 1983.

5. Holtan SG, Creedon DJ, Haluska P and Markovic SN: Cancer and pregnancy: Parallels in growth, invasion, and immune modulation and implications for cancer therapeutic agents. Mayo Clin Proc 84: 985-1000, 2009.

6. Rozhok AI and DeGregori J: Toward an evolutionary model of cancer: Considering the mechanisms that govern the fate of somatic mutations. Proc Natl Acad Sci USA 112: 8914-8921, 2015.

7. Sell S, Nicolini A, Ferrari P and Biava PM: Cancer: A problem of developmental biology; scientific evidence for reprogramming and differentiation therapy. Curr Drug Targets 17: 1103-1110, 2015.

8. Xiao T, Ying W, Li L, Hu Z, Ma Y, Jiao L, Ma J, Cai Y, Lin D, Guo Si, et al: An approach to studying lung cancer-related proteins in human blood. Mol Cell Proteomics 4: 1480-1486, 2005.

9. Skinner J, Kotliarov Y, Varma S, Mine KL, Yambartsev A, Simon R, Huyen Y, Morgun A: Construct and compare gene coexpression networks with DAPfinder and DAPview. BMC Bioinformatics 12: 286, 2011.

10. Mootha VK, Lindgren CM, Eriksson KF, Subramanian A, Sihag S, Lehar J, Puigserver P, Carlsson E, Ridderstråle M, Laurila E, et al: PGC-1alpha-responsive genes involved in oxidative phosphorylation are coordinately downregulated in human diabetes. Nat Genet 34: 267-273, 2003.

11. Subramanian A, Tamayo P, Mootha VK, Mukherjee S, Ebert BL, Gillette MA, Paulovich A, Pomeroy SL, Golub TR, Lander ES, et al: Gene set enrichment analysis: A knowledge-based approach for interpreting genome-wide expression profiles. Proc Natl Acad Sci USA 102: 15545-15550, 2005.

12. Winn VD, Haimov-Kochman R, Paquet AC, Yang YJ, Madhusudhan MS, Gormley M, Feng KT, Bernlohr DA, McDonagh S, Pereira L, et al: Gene expression profiling of the human maternal-fetal interface reveals dramatic changes between midgestation and term. Endocrinology 148: 1059-1079, 2007.

13. Kang TH, Park Y, Bader JS and Friedmann T: The housekeeping gene hypoxanthine guanine phosphoribosyltransferase (HPRT) regulates multiple developmental and metabolic pathways of murine embryonic stem cell neuronal differentiation. PLoS One 8: e74967, 2013.

14. Hofmann UB, Eggert AA, Blass K, Bröcker EB and Becker JC: Expression of matrix metalloproteinases in the microenvironment of spontaneous and experimental melanoma metastases reflects the requirements for tumor formation. Cancer Res 63: 8221-8225, 2003.

15. Murray MJ and Lessey BA: Embryo implantation and tumor metastasis: Common pathways of invasion and angiogenesis. Semin Reprod Endocrinol 17: 275-290, 1999.

16. Dvorak P, Dvorakova D and Hampl A: Fibroblast growth factor signaling in embryonic and cancer stem cells. FEBS Lett 580: 2869-2874, 2006.

17. Xu P, Wang Y, Piao Y, Bai S, Xiao Z, Jia Y, Luo S and Zhuang L: Effects of matrix proteins on the expression of matrix metalloproteinase- $2,-9$, and -14 and tissue inhibitors of metalloproteinases in human cytotrophoblast cells during the first trimester. Biol Reprod 65: 240-246, 2001.

18. Umezawa M, Saito Y, Tanaka-Hattori N, Takeda K, Ihara T and Sugamata M: Expression profile of extracellular matrix and adhesion molecules in the development of endometriosis in a mouse model. Reprod Sci 19: 1365-1372, 2012.

19. Hu Z, Lin D, Yuan J, Xiao T, Zhang H, Sun W, Han N, Ma Y, Di X, Gao M,et al: Overexpression of osteopontin is associated with more aggressive phenotypes in human non-small cell lung cancer. Clin Cancer Res Clin Cancer Res 11: 4646-4652, 2005. 
20. Liu Y, Lin D, Xiao T, Ma Y, Hu Z, Zheng H, Zheng S, Liu Y, Li M, Li L, et al: An immunohistochemical analysis-based decision tree model for estimating the risk of lymphatic metastasis in pN0 squamous cell carcinomas of the lung. Histopathology 59: 882-891, 2011

21. Borm PJ and Driscoll K: Particles, inflammation and respiratory tract carcinogenesis. Toxicol Lett 88: 109-113, 1996.

22. Driscoll KE: Role of inflammation in the development of rat lung tumors in response to chronic particle exposure. Inhalation Toxicology 8: 139-153, 1996.

23. Driscoll KE, Deyo LC, Carter JM, Howard BW, Hassenbein DG and Bertram TA: Effects of particle exposure and particle-elicited inflammatory cells on mutation in rat alveolar epithelial cells. Carcinogenesis 18: 423-430, 1997.
24. Tsai MS, Weng SH, Chen HJ, Chiu YF, Huang YC, Tseng SC, Kuo YH and Lin YW: Inhibition of p38 MAPK-dependent excision repair cross-complementing 1 expression decreases the DNA repair capacity to sensitize lung cancer cells to etoposide. Mol Cancer Ther 11: 561-571, 2012.

25. Sarker AH, Chatterjee A, Williams M, Lin S, Havel C, Jacob P III, Boldogh I, Hazra TK, Talbot P and Hang B: NEIL2 protects against oxidative DNA damage induced by sidestream smoke in human cells. PloS One 9: e90261, 2014.

26. Reya T, Morrison SJ, Clarke MF and Weissman IL: Stem cells, cancer, and cancer stem cells. Nature 414: 105-111, 2001. 